\title{
Article \\ Identification and Genomic Characterization of Pathogenic Bacillus altitudinis from Common Pear Trees in Morocco
}

\author{
Naima Lemjiber ${ }^{1, *}$, Khalid Naamani ${ }^{1, *}$, Annabelle Merieau ${ }^{2,3}$, Abdelhi Dihazi ${ }^{4}$, Nawal Zhar ${ }^{1}$, Hicham Jediyi ${ }^{1}$ \\ and Amine M. Boukerb 2,5,*iD
}

1 Laboratory of Pharmacology, Neurobiology, Anthropobiology and Environment, Team of Protection and Valorization of Vegetable Resources, Faculty of Sciences Semlalia Marrakesh, Cadi Ayyad University, My Abdallah Street, PB-2390, Marrakesh 40000, Morocco; nawal.zhar@edu.uca.ac.ma (N.Z.); jedhicham@gmail.com (H.J.)

2 Laboratory of Microbiology, Signals and Microenvironment LMSM EA 4312, University of Rouen-Normandy, Normandy University, 27000 Evreux, France; annabelle.merieau@univ-rouen.fr

3 SFR NORVEGE, Structure Fédérative de Recherche Normandie Végétale, FED 4277, F-76821 Mont-Saint-Aignan, France

4 Laboratory of Agrobiotechnology and Bioengineering, FSTM, Department of Biology, Cadi Ayyad University, 112 Abdelkrim Al Khattabi Street, Marrakesh 40000, Morocco; dihazi_abdel@yahoo.fr

5 Genomics Platform, LMSM EA 4312, University of Rouen-Normandy, Normandy University, 27000 Evreux, France

* Correspondence: naima.lemjiber2012@gmail.com (N.L.); naamani@uca.ac.ma (K.N.); amine.boukerb@univ-rouen.fr (A.M.B.)

\section{check for} updates

Citation: Lemjiber, N.; Naamani, K.; Merieau, A.; Dihazi, A.; Zhar, N.;

Jediyi, H.; Boukerb, A.M.

Identification and Genomic

Characterization of Pathogenic

Bacillus altitudinis from Common Pear Trees in Morocco. Agronomy 2021, 11, 1344. https://doi.org/10.3390/ agronomy11071344

Academic Editors:

Muhammad Shahid and Ali Sarkhosh

Received: 20 May 2021

Accepted: 28 June 2021

Published: 30 June 2021

Publisher's Note: MDPI stays neutra with regard to jurisdictional claims in published maps and institutional affiliations.

Copyright: (c) 2021 by the authors. Licensee MDPI, Basel, Switzerland. This article is an open access article distributed under the terms and conditions of the Creative Commons Attribution (CC BY) license (https:// creativecommons.org/licenses/by/ $4.0 /)$
Abstract: Bacterial burn is one of the major diseases affecting pear trees worldwide, with serious impacts on producers and economy. In Morocco, several pear trees (Pyrus communis) have shown leaf burns since 2015. To characterize the causal agent of this disease, we isolated fourteen bacterial strains from different parts of symptomatic pear trees (leaves, shoots, fruits and flowers) that were tested in planta for their pathogenicity on Louise bonne and Williams cultivars. The results showed necrotic lesions with a significant severity range from 47.63 to $57.77 \%$ on leaves of the Louise bonne cultivar inoculated with isolate B10, while the other bacterial isolates did not induce any disease symptom. $16 \mathrm{~S}$ rRNA gene sequencing did not allow robust taxonomic discrimination of the incriminated isolate. Thus, we conducted whole-genome sequencing (WGS) and phylogenetic analyzes based on gyr $A$, gyrB and $c d a A$ gene sequences, indicating that this isolate belongs to the Bacillus altitudinis species. This taxonomic classification was further confirmed by the Average Nucleotide Identity (ANI) and the in silico DNA-DNA hybridization (isDDH) analyzes compared to sixty-five Bacillus spp. type strains. The genome was mined for genes encoding carbohydrate-active enzymes (CAZymes) known to play a role in the vegetal tissue degradation. 177 candidates with functions that may support the in planta phytopathogenicity results were identified. To the best of our knowledge, this is the first data reporting B. altitudinis as agent of leaf burn in P. communis in Morocco. Our dataset will improve our knowledge on spread and pathogenicity of $B$. altitudinis genotypes that appears as emergent phytopathogenic agent, unveiling virulence factors and their genomic location (i.e., within genomic islands or the accessory genome) to induce trees disease.

Keywords: greenhouse; infiltration; next generation sequencing; pathovar; phylogeny; spray; virulence factors

\section{Introduction}

Common pear (Pyrus communis) is one of the main consumed fruits worldwide [1] with a production of around 25.2 million tons per year [2]. This fruit has a high nutritional value and represents a source of different vitamins and minerals [3]. In Morocco, pear trees were reported to occupy 3522 ha and the production varies according to climate variation, water supply and spread of diseases. In 2016, the production of pear fruit was 
about 27,754 tons [4]. Unfortunately, this crop is prone to several diseases caused by several phytopathogens that affect growth and production of pear trees. This includes diseases such as the brown spot caused by Stemphylium vesicarium $[5,6]$, the leaf scorch caused by Xylella fastidiosa [7], the soft rot caused by Bacillus altitudinis [8], the anthracnose disease caused by Colletotrichum acutatum [9] and the fire blight caused by Erwinia amylovora [10,11], which all are the most devastating bacterial or fungal diseases of pear worldwide with high economic losses [12].

In Morocco, little is known about pear diseases and the damages begotten by bacterial pathogens. Therefore, it becomes necessary to identify the causal agents in order to establish the appropriate strategies to control pear diseases. To the best of our knowledge, in Morocco only one study has been conducted in Ain Orma of the Meknes region [13]. During our survey, the burnt trees were observed with diseases in two pear farms in Asni province at El Haouz of the Marrakesh region. The disease symptoms were observed on leaves, fruits and shoot, similar to those caused by Erwinia amylovora. In a previous study, Kotan et al. [14] indicated that several bacterial species (i.e., Erwinia amylovora, Pseudomonas. syringae pv. syringae, Erwinia rhapontici, Pseudomonas putida, Pseudomonas huttiensis, Chromobacterium violaceum, Pantoea agglomerans, Achromobacter piechaudii, Bacillus pumilus GC subgroup B, Echinococcus intermedius, Pseudomonas aeruginosa and Pseudomonas cichorii) cause similar necrotic lesions on apple leaves.

The Bacillus genus brings together many of the most widely disseminated species in the environment. Bacteria belonging to this genus form spores that allow them to survive in extreme conditions [15]. Numerous studies have shown the role of biocontrol agents of few species. For instance, B. subtilis is well known for its antagonistic activities against several plant diseases caused by many fungi and bacteria [16,17]. Other species of the genus Bacillus were reported as responsible for infections in humans, e.g., B. anthracis and B. cereus. Other studies demonstrated that some Bacillus species are phytopathogens. For example, $B$. polymyxa and $B$. circulans were shown to cause soft rot in various types of vegetables and fruit crops [18,19]. In Egypt, B. pumilus was reported to cause leaf blight in mango trees [20], and a bacterial blotch of immature Balady peach [21]. On pome fruits, B. pumilus was also reported as responsible for Golden Delicious apple necrotic lesions in the Eastern Anatolia region of Turkey [14]. Furthermore, Li et al. [22] reported that the twig dieback disease on the Asian pear trees (Pyrus pyrifolia) was associated to B. pumilus infection.

The disease symptoms on pear trees described by local farmers were characterized by shoots drying and wilting, fruits browning and drying, branches and twigs burnt and secretion of exudate. Even though, in the absence of methods to contain this infectious disease, the cutting and destruction of infected parts remain the only strategy to mitigate the spread of the infection from one tree to another.

The diagnosis of plant diseases depends on the identification of the pathogens. While the use of biochemical tests to identify bacteria belonging to Bacillus genus is classical [23], molecular biology techniques have become a complementary tool to study bacterial diversity [24]. For example, the amplification and sequencing of the 16S rRNA gene is widely used as a biomarker for the identification and taxonomic classification of bacteria and archaea. This gene has a conserved sequence with a low mutation rate. The use of 16S rRNA gene in identifying closely related bacterial species, such as the species belonging to the $B$. pumilus group, may be difficult due to its highly conserved sequences within this group. In addition, these genes can undergo occasional lateral transfer or recombination [25]. The other disadvantage associated with the use of 16S rRNA gene is the presence of a variable number of copies. Therefore, other molecular markers would be helpful in discriminating the taxonomic affiliation of targeted species.

The symptoms observed in pear trees at Asni province in Morocco may be associated to diverse pathogenic bacteria. Thus, the aim of the present study was to isolate and identify the causative agent of these symptoms. Preliminary isolation suggests the presence of bacterial isolates in infected plants that were further investigated using (i) the in planta pathogenicity tests for disease severity estimation, (ii) the Whole Genome Sequencing for 
taxonomic classification and (iii) the in silico pathogenicity evaluation to decipher potential virulence factors. These analyzes may unveil the association of a specific $B$. altitudinis genotype to pear trees bacterial burn disease. To the best of our knowledge, this is the first study on the identification of B. altitudinis as pear tree pathogen in Morocco.

\section{Materials and Methods}

\subsection{Plants Sampling and Bacterial Strains Isolation}

Samples of infected pear trees (leaves, shoots, fruits and flowers) showing bacterial burn symptoms were collected from Asni (Marrakesh region of Morocco; $31^{\circ} 14^{\prime} 41.93^{\prime \prime} \mathrm{N}$ and $\left.7^{\circ} 58^{\prime} 56.79^{\prime \prime} \mathrm{W}\right)$. They were immediately sliced into small fragments, washed twice with sterile distilled water (SDW) and surface sterilized with Sodium Hypochlorite (0.5\%) for $30 \mathrm{~s}$, then placed in SDW for $30 \mathrm{~min}$. Later, serial dilutions from $10^{-1}$ to $10^{-6}$ of the samples were realized in saline solution (water with $0.9 \% \mathrm{NaCl}$ ). King's B agar culture medium [proteose peptone $20 \mathrm{~g} / \mathrm{L}$, dipotassium hydrogen phosphate $1.5 \mathrm{~g} / \mathrm{L}$, magnesium sulphate $1.5 \mathrm{~g} / \mathrm{L}$, glycerol $15 \mathrm{~mL} / \mathrm{L}$ and agar $15 \mathrm{~g} / \mathrm{L}$ (Sigma Aldrich, USA)] was used for bacterial culture. After incubation at $30^{\circ} \mathrm{C}$ for $24 \mathrm{~h}$, fourteen isolates (named B1 to B14) were obtained and transferred to a new King's B agar medium. Each culture was presumed pure after four successive subcultures on the same medium.

\subsection{Pathogenicity Test}

\subsubsection{Plant Material}

The plant material was composed of two pear cultivars (cv. Louise bonne and cv. Williams). They were grown under natural photoperiod at $17^{\circ} \mathrm{C}$ to $28^{\circ} \mathrm{C}$ in a greenhouse.

\subsubsection{Preparation of Bacterial Inoculum}

This was achieved according to Peng et al. [26]. The isolates $(n=14)$ were grown at $30{ }^{\circ} \mathrm{C}$ on King's B agar medium for $24 \mathrm{~h}$. The bacteria were collected and suspended in saline solution, and the concentration was adjusted to $10^{9} \mathrm{CFU} / \mathrm{mL}$ that corresponds to an optical density $\left(\mathrm{OD}_{600}\right)$ of 0.5 .

\subsubsection{Pathogenicity Tests}

The pathogenicity tests were performed according to Cesbron et al. [27]. After one month of growing in the greenhouse, the plants were sprayed with distilled water before inoculation and kept under a transparent plastic film shelter to maintain the humidity at saturation. Two inoculation methods were applied for each bacterial isolate: the spray inoculation and the infiltration method. In addition, control group of plants were inoculated with saline solution.

\subsection{Infiltration Method}

Bacterial inoculum was taken in a disposable injection syringe of $0.5 \mathrm{~mL}$ capacity. The syringe needle was placed on the leaf's underside, particularly at the interveinal region, then, the inoculum was softly injected. The leaf was firmly held by providing support on the opposite side at the injection point (mouth of the needle). The injection was carefully accomplished to avoid wounds at the point of injection. Plants were incubated in humid conditions, according to Patil et al. [28]. This method is the most common and fast, facilitating the penetration of bacteria inside the leaves without causing additional injuries.

\subsection{Spraying Method}

Plants were sprayed on the foliage using a hand sprayer.

After using the two methods, plants were first incubated inside the shelter for $2 \mathrm{~h}$, then in normal greenhouse conditions outside the shelter, under natural photoperiod at $17^{\circ} \mathrm{C}$ to $28^{\circ} \mathrm{C}$. These steps are necessary and may improve natural infection to achieve uniform disease pressure [29]. For each bacterial isolate, five pear plants of either Williams or Louise bonne variety were used for the pathogenicity test. Saline solution was used 
as control within the two methods. To confirm Koch's postulate and to ensure that the observed symptoms were due to the same pathogen, we performed a re-isolation of the bacterium from infected leaves of $\mathrm{cv}$. Louis bonne and identified the isolate by whole genome sequencing.

\subsection{Disease Assessment}

ImageJ v1.45 [30] was used to calculate the total area of each leaf, as well as the areas of the necrotic lesions. A digital image composed of pixels was converted to centimeters using the photo filter software version 7 . After manually drawing the region of interest (total area and areas of necrotic lesion on each leaf), the area was measured and noted in the spreadsheet.

The percentage of infection was calculated according to the following formula:

Percentage of infection $=[($ total area of the necrotic lesions $) /($ total area of the leaf $)] \times 100$

The percentage of severity was evaluated according to the percentage of the infection and using a scale based on symptoms and ranged from 0 to 5 ( 0 , no visible symptoms; 1 , $1-25 \%$ of leaf area infection; $2,26-50 \%$ of leaf area infection; $3,51-75 \%$ of leaf area infection; and $5,>76 \%$ with highly blighted pear leaves). The following formula was used:

Percentage of severity $=[($ number of infected leaves $\times$ its grade $) /($ number of observed leaves $)] \times 100$

Statistical analyzes were performed within $R$ version 4.0.3 [31]. Non-parametric Kruskall-Wallis test was performed to investigate percentages of severity. Five repetitions were accomplished for each cultivar (i.e., Louise bonne and Williams), in addition to the controls exposed to saline solution. The statistical significance level was set at a $p$-value of 0.05 .

\subsection{Molecular Identification}

The $16 \mathrm{~S}$ rRNA gene of B10 isolate was amplified by PCR using universal primers 27F (5'-AGAGTTTGATCCTGGCTCAG-3') and 1492R (5'-CGGTTACCTTGTTACGACTT-3'). Initial denaturation was set at $95^{\circ} \mathrm{C}$ for $5 \mathrm{~min}$, followed by 25 cycles of denaturation at $95^{\circ} \mathrm{C}$ for $45 \mathrm{~s}$, annealing at $50{ }^{\circ} \mathrm{C}$ for $45 \mathrm{~s}$ and extension at $72{ }^{\circ} \mathrm{C}$ for $90 \mathrm{~s}$, followed by a final elongation step at $72{ }^{\circ} \mathrm{C}$ for $2 \mathrm{~min}$ and $4{ }^{\circ} \mathrm{C}$ forever. The polymerase used in this assay was the high-fidelity PCR enzyme (Thermo Fisher). The obtained amplicons were sent to Genewiz Los Angeles Metro (USA) for Sanger sequencing.

The $16 \mathrm{~S}$ rRNA sequence was initially analyzed using the BLAST software on the NCBI (National Center Biotechnology Information, http//:www.ncbi.nml.nih.gov, accessed on 18 January 2021) and compared with the Reference RNA sequences (refseq rna) database.

\subsection{Genomic DNA Extraction and Whole Genome Sequencing}

The original isolate B10 and the B10-bis strain re-isolated from plants developing of disease were inoculated in $5 \mathrm{~mL}$ of nutrient broths and incubated overnight at $37^{\circ} \mathrm{C}$. Genomic DNA was extracted using the GeneJET Genomic DNA Purification kit (Thermo Fisher Scientific, Sunnyvale, CA, USA) according to the manufacturer's instructions for lysis of Gram-positive bacteria. The quality and concentration of DNA were determined on a Nanodrop spectrophotometer and a Qubit 4.0 fluorometer (Thermo Fisher Scientific, USA). The DNA integrity was monitored through electrophoresis using a $0.8 \%$ agarose gel followed by Syber-safe staining (Thermo Fisher Scientific, USA) and visualized on a UV transilluminator. Libraries for both B10 and B10-bis were prepared using the Illumina DNA Prep kit (Illumina) and sequenced on a MiSeq platform (LMSM EA 4312, Rouen Normandy University, Evreux, France) according to the manufacturer's protocol, with the MiSeq reagent cartridge V3 (600 cycles, 300-bp dual-index paired-end reads). 


\subsection{Bioinformatics}

\subsubsection{Genome Assembly and Annotation}

Default parameters were applied for each software unless otherwise specified. Sequence data quality was assessed using FastQC software v.0.11.9 [32]. Low-quality reads and adapters were trimmed using Trimmomatic v.0.39 [33]. Genome assembly was achieved de novo with Unicycler v.0.4.8 [34]. Quast v.5.0.2 [35] was used to check the consistency of the obtained assembly (i.e., genome size, number of contigs, $\mathrm{N}_{50}$ and $\mathrm{G}+\mathrm{C}$ content). Mean coverage of contigs was determined by mapping trimmed reads onto the contigs using BBMap v.38.18 [36]. The assembled contigs were annotated using the NCBI prokaryotic genome automatic annotation pipeline (PGAP) [37].

\subsubsection{Phylogenetic Analysis}

The high-quality genome sequence of the B10 isolate was used to determine its taxonomic affiliation. The sequences of the $16 \mathrm{~S}$ rRNA, gyrA, gyrB and $c d a A$ genes were extracted from the annotated contigs. These sequences were further aligned and compared to the corresponding gene sequences from a selection of Bacillus species representing valid type strains of the genus: multiple sequence alignments were performed using clustalW, and inferring phylogenetic trees using the neighbor-joining method (with the Kimura 2-parameter model) and 1000 bootstrap iterations using MEGA 10.2.2 [38].

\subsubsection{Genome Indexes}

Whole-genome data from Bacillus sp. B10 and sixty-five taxonomically validated Bacillus species were compared against each other using average nucleotide identity analysis based on BLAST (ANIb) within Pyani [39], and the in silico DNA-DNA hybridization (isDDH) was calculated using the GGDC web server (http:/ / ggdc.dsmz.de, accessed on 8 March 2021) [40].

\subsubsection{Identification of Carbohydrate-Active Enzymes}

The dbCAN annotation tool for automated carbohydrate-active enzymes (CAZyme) annotation, Run-dbcan v2.0.11 (https:/ / github.com/linnabrown/run_dbcan, accessed on 10 May 2021) [41], was used with default parameters to predict CAZymes using CAZyDB version 07312020 . CAZymes were grouped based on the substrates and the corresponding Merops families [42].

\section{Results}

\subsection{Pathogenicity Tests}

For all tested bacterial strains on Williams cv, no symptoms were observed, and no significant difference was noted compared to the controls $(p>0.05)$, regardless of the inoculation method (Figure 1e). However, on Louis bonne cv, the symptoms were observed only for the isolate B10 after two weeks of inoculation by spraying method. The severity ranged from $47.63 \%$ to $57.77 \%$ for $25 \%$ of B10-infected leaves (Figure 1a,c and Figure 2). Control plants or those treated with the other isolates (thirteen isolates) showed no significant symptoms versus B10 isolate $(p<0.001)$ (Figure 2$)$.

For the infiltration method, small and limited necrotic spots on Louise bonne cv. appeared after 10 days of inoculation with B10 isolate (Figure 1b,d). In contrast, control plants exposed to saline solution were found asymptomatic (Figure 1f). The spray method using B10 isolate resulted in a clearly defined necrosis where leaves wilted rapidly, then turned to light brown and finally dried out. The bacterium re-isolated from symptomatic plant (cv. Louise bonne) was named strain B10-bis and thereafter characterized by wholegenome analysis compared to the inoculum B10. 


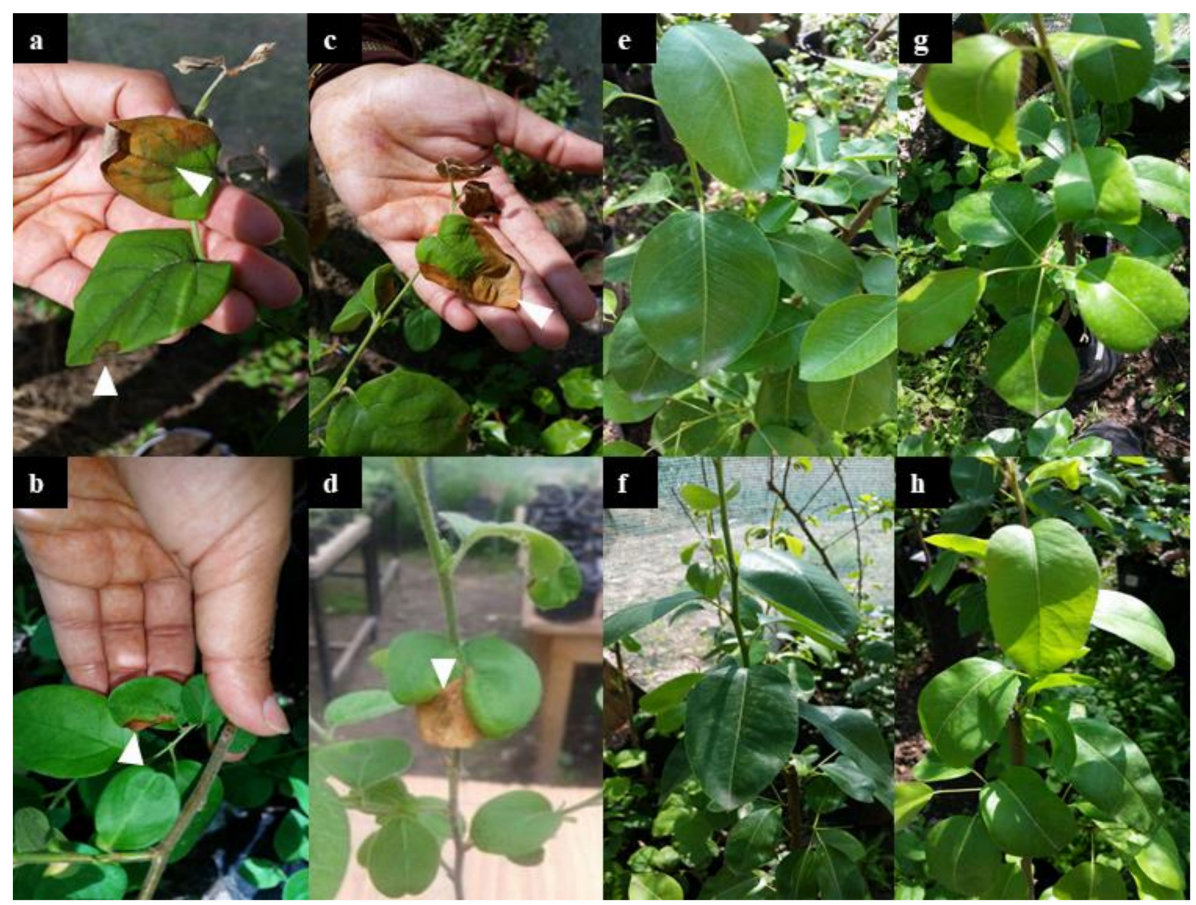

Figure 1. Pathogenicity tests on pear plants grown in greenhouse after fifteen days of inoculation. For Louise bonne cultivar exposed to B10 isolate, panels $(\mathbf{a}, \mathbf{c})$ represent symptoms developed using the spray method, (b,d) symptoms observed by the infiltration method. Panel (e) shows no symptoms on Williams cultivar inoculated with B10 isolate, (f) shows no symptoms on control plants of Williams $\mathrm{cv}$ and (g,h) shows no symptoms on leaves inoculated by other isolates (B13 and B2) on Louise bonne cultivar.

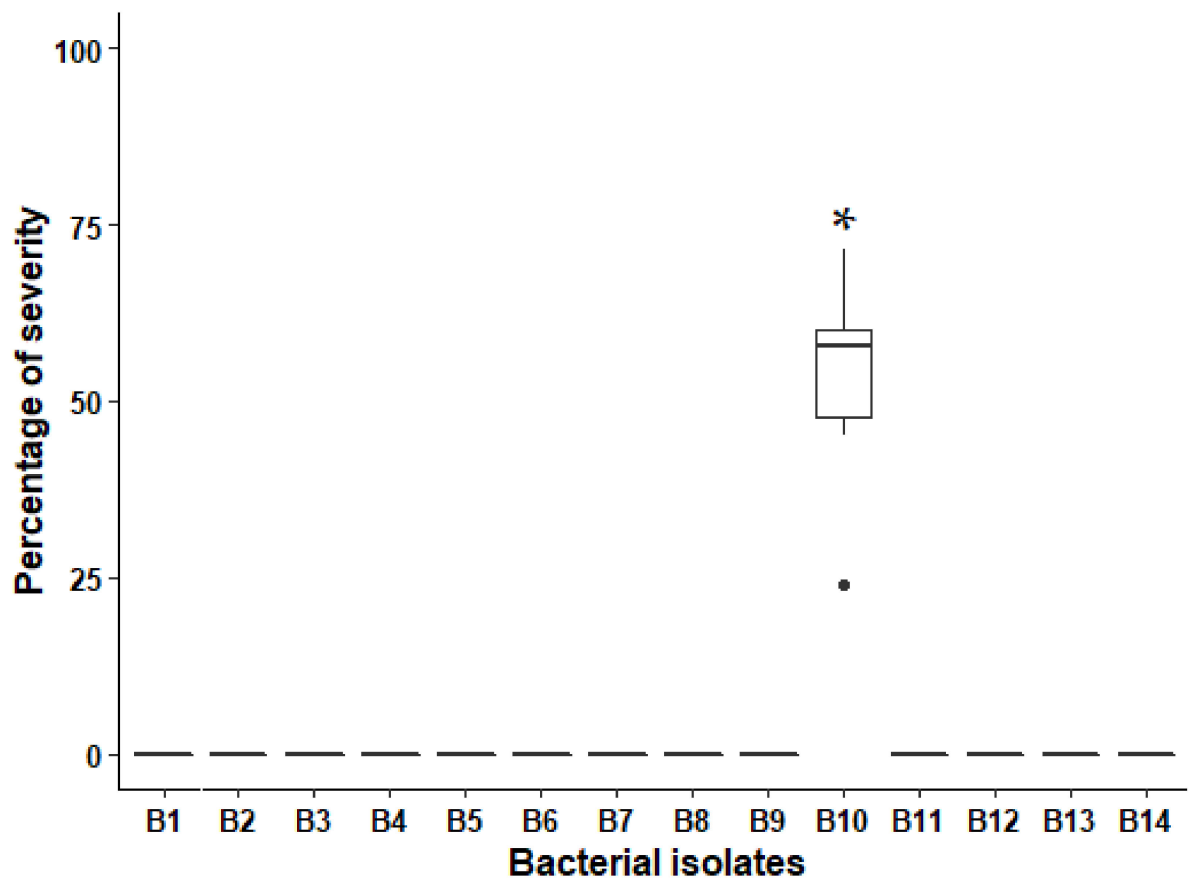

Figure 2. Boxplots of severity percentages calculated for exposed leaves to the fourteen bacterial isolates on Louise bonne cultivar using the spray method. Controls gave similar results as the non-pathogenic isolates (data not shown). Boxes represent the interquartile range, whiskers show the 10th and 90th percentiles and individual outliers are shown as points (Kruskal-Wallis test with ${ }^{*} p<0.001$ ). 


\subsection{Taxonomic Identification of the Bacterial Isolate B10}

The B10 isolate causing symptoms in pear trees in greenhouse conditions was subjected to molecular identification. The result of the $16 \mathrm{~S}$ rRNA sequence alignment with BLASTn showed a very strong homology (99.84\%) with B. pumilus, B. safensis and Bacillus $s p$. Thus, we conducted the whole-genome sequencing of both B10 and B10-bis (re-isolated from infected plants) isolates to acquire their precise taxonomic affiliation. For both strains, the DNA G + C content was $41.27 \%$ and draft genome size of about 3,6 Mb (Table 1). The full size of the 16S rRNA gene sequences obtained by genome annotation of both strains were $1516 \mathrm{bp}$ and shared $100 \%$ identity. The ANI and is DDH analyzes of both genomes gave scores of $100 \%$, indicating that we were dealing with the same bacterial strain that was isolated twice. Thus, for the downstream analyzes, focus was made on WGS data from the B10 isolate. Details of assembly metrics and GenBank accession number for both isolates are provided in Table 1.

Table 1. Sequencing metrics and genomic data.

\begin{tabular}{ccc}
\hline Parameter & \multicolumn{2}{c}{ Data for Strain } \\
\cline { 2 - 3 } & Bacillus altitudinis B10-bis & Bacillus altitudinis B10 \\
\hline Location & Greenhouse & Field \\
\hline DNA library prep kit & DNA Prep kit (Illumina) $(2 \times 300)$ & DNA Prep kit (Illumina) $(2 \times 300)$ \\
\hline Sequencing metrics & $2,030,980$ & $2,169,478$ \\
No. Of total reads & 123 & 136 \\
Mean coverage $(\times)$ & & JAGSNB000000000 \\
\hline Accession no. & na & $3,648,564$ \\
GenBank & $3,649,248$ & 41.27 \\
Genomic data & 41.27 & 48 \\
Genome size $(b p)$ & 44 & 293,183 \\
G + C content $(\%)$ & 293,183 & \\
No. of contigs & & \\
N50 $(b p)$ & $n+183$ & \\
\hline
\end{tabular}

na. not available.

First, phylogenetic analysis of the 16S rRNA gene was achieved against selected type strains from Bacillus genus. The obtained neighbor-joining tree (Figure 3) shows $\mathrm{B} 10$ to be related to B. altitudinis, B. aerophilus and B. xianmenensi. This result suggests that $\mathrm{B} 10$ belong to the $B$. pumilus group, but the $16 \mathrm{~S}$ rRNA phylogeny is not sufficient to discriminate the exact species. Thus, we used three other genes as alternative molecular markers: gyrA, gyrB and $c d a A$. Regarding the phylogenetic tree of the $c d a A$ gene, strain B10 appears to have identity with strain B. altitudinis DSM $21631^{\mathrm{T}}$ with a bootstrap value of $79 \%$ (Figure 4). Similar result was obtained with the phylogenetic tree constructed from the gyr $A$ gene sequences (Figure 5). The results of the identification based on the gyrB gene sequence analysis presented in Figure 6 also indicate a high identity with the B. altitudinis DSM $21631^{\mathrm{T}}$ strain with a bootstrap value of $100 \%$.

To further investigate the taxonomic classification of the isolate B10, we calculated genome-related indexes between the genome sequence of this strain and the genomes of the closest species: the Average Nucleotide Identity (ANI) with values $>97 \%$, and the in silico DNA-DNA hybridization (is DDH) with values $>70 \%$, indicate belonging to the same species (Figure 7 and Table 2). Thus, the obtained results also classified the isolate $\mathrm{B} 10$ as $B$. altitudinis, confirming the results obtained by analyzing the $c d a A, g y r A$ and gyrB phylogenies. 


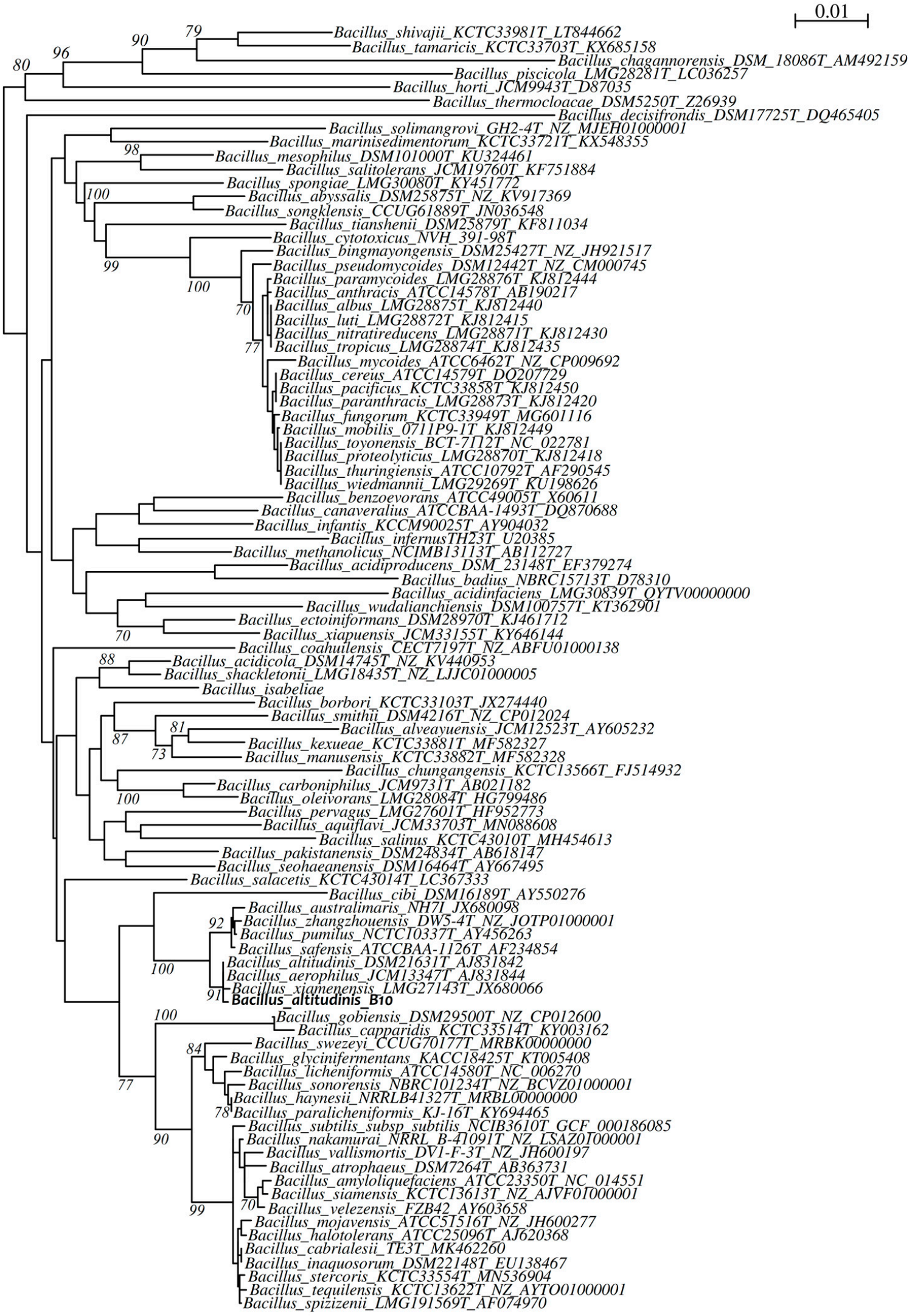

Figure 3. Neighbor-joining phylogenetic tree based on $16 \mathrm{~S}$ rRNA gene sequences showing the positions of the B10 isolate belonging to B. pumilus group and the type strains of the genus Bacillus. Bootstrap values $>70$ are shown above branches. Bar: 0.01 substitutions per nucleotide position. Sequence accession numbers are given following strain IDs. 


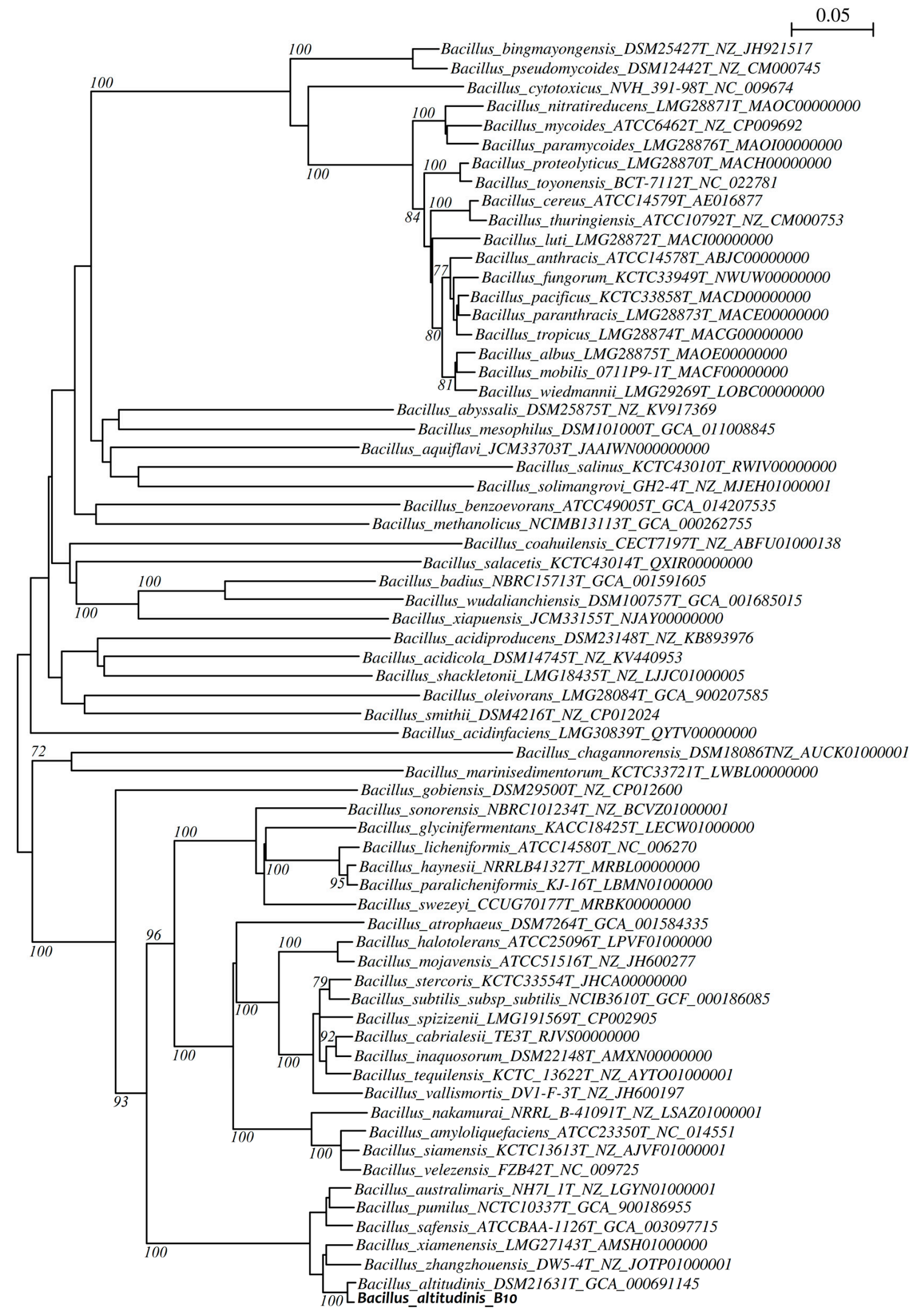

Figure 4. Neighbor-joining phylogenetic tree based on $c d a A$ gene sequences showing the positions of the B10 isolate B. altitudinis and the type strains of the genus Bacillus. Bootstrap values $>70$ are shown above branches. Bar: 0.05 substitutions per nucleotide position. Sequence accession numbers are given following strain IDs. 


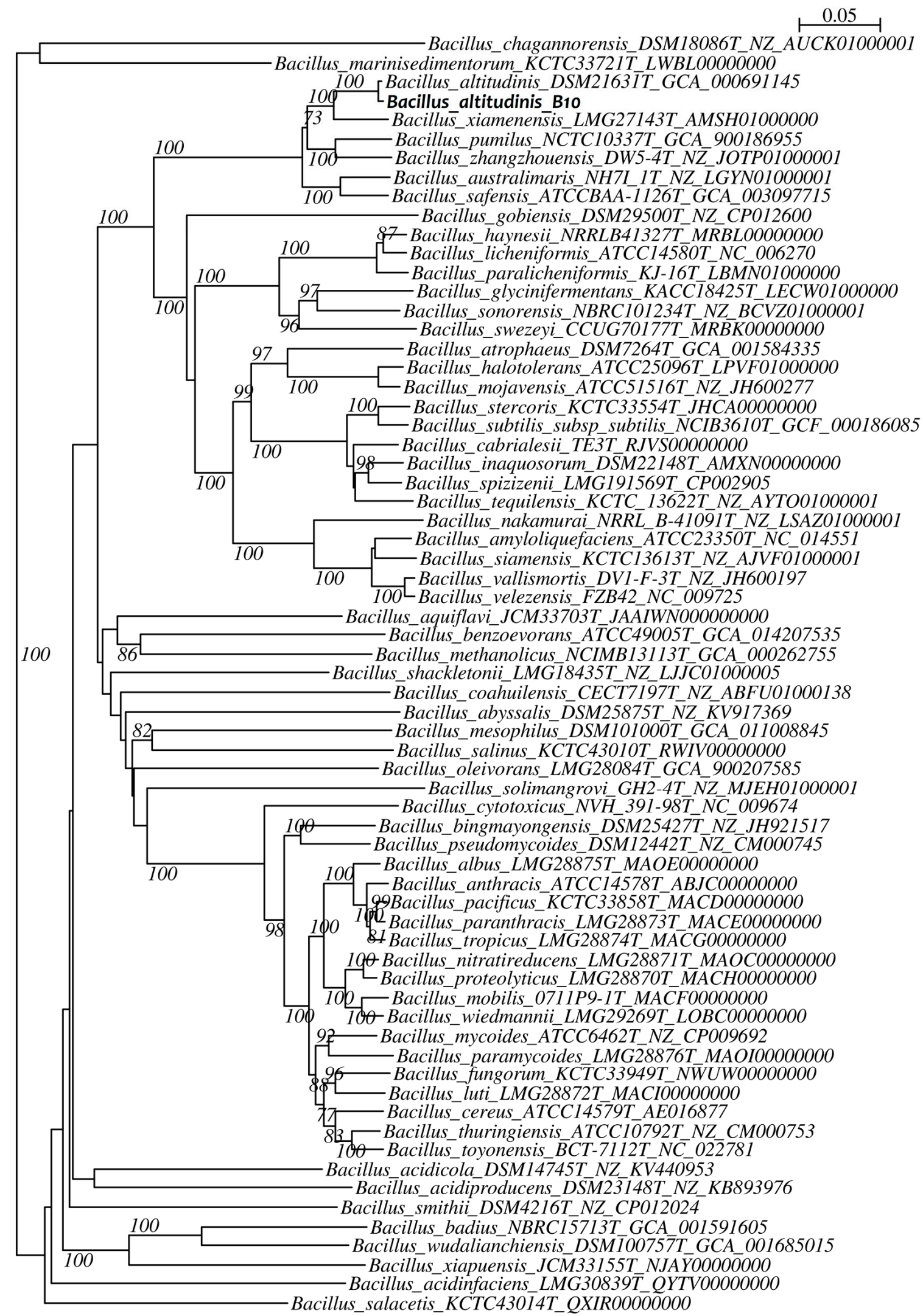

Figure 5. Neighbor-joining phylogenetic tree based on gyrA gene sequences showing the positions of the B10 isolate B. altitudinis and the type strains of the genus Bacillus. Bootstrap values $>70$ are shown above branches. Bar: 0.05 substitutions per nucleotide position. Sequence accession numbers are given following strain IDs. 


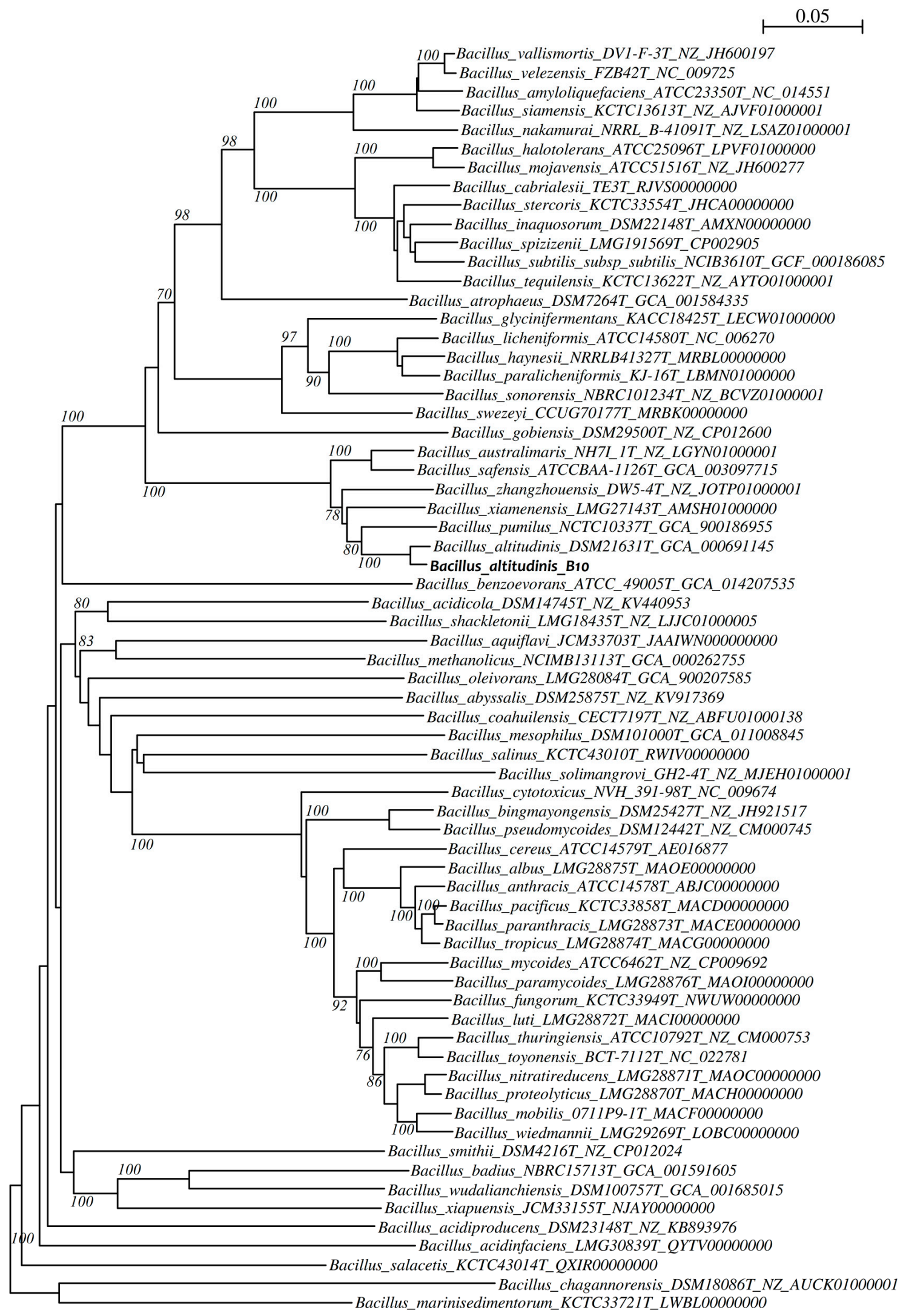

Figure 6. Neighbor-joining phylogenetic tree based on gyrB gene sequences showing the positions of the B10 isolate B. altitudinis and the type strains of the genus Bacillus. Bootstrap values $>70$ are shown above branches. Bar: 0.05 substitutions per nucleotide position. Sequence accession numbers are given following strain IDs. 


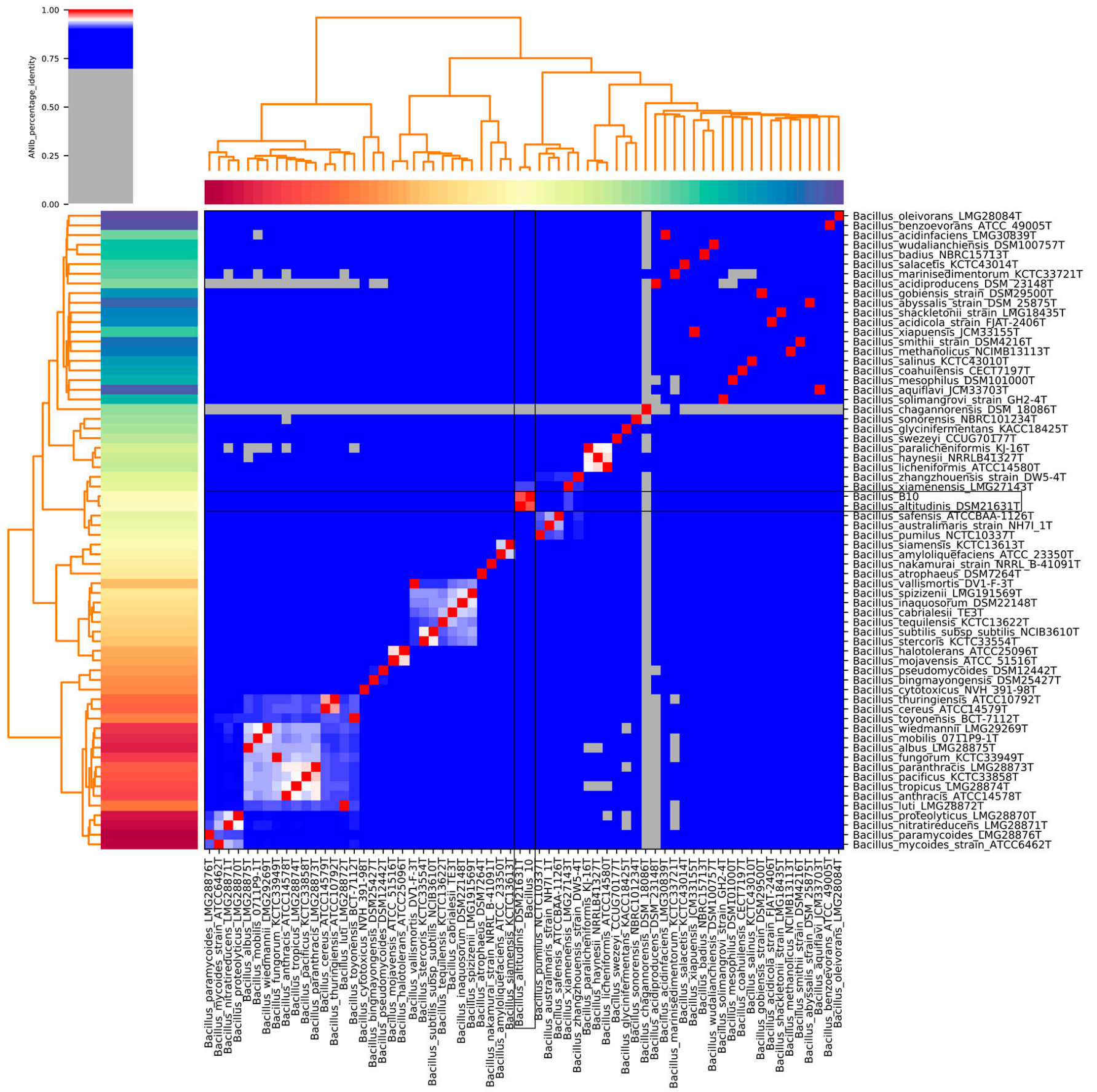

Figure 7. Average Nucleotide Identity (ANI) based on BLAST among Bacillus sp. B10 and type strains of the genus Bacillus. The ANI was calculated using the Pyani program after BLASTn alignment. The ANI above $97 \%$ between two genomes is an indication that they belong to the same species.

\subsection{CAZyme Profiling}

In silico screening of CAZymes within B10 genome sequence showed that this isolate encodes 177 putative genes (Table S1). Six classes were identified including carbohydrate esterases (CE, $n=21)$, glycoside hydrolases $(\mathrm{GH}, n=34)$ and polysaccharide lyases (PL, $n=2)$ that are known as plant cell wall degrading enzymes. The three other classes with indirect roles in degrading carbohydrates are auxiliary activity (AA, $n=3)$, carbohydrate binding module (CBM, $n=19)$ and glycosyl-transferase (GT, $n=38)$. 
Table 2. Average nucleotide identity based on BLAST (ANIb) and pairwise in silico DNA-DNA hybridization (isDDH) using GGDC formula 2 values for the Bacillus sp. B10 isolate and the most closely related members of the genus Bacillus. The numbers below the diagonal are ANI values predicted between pairs of genomes. The numbers above the diagonal are is DDH values between genomes. Strains: 1, Bacillus sp. B10; 2, B. altitudinis DSM21631 ${ }^{\mathrm{T}}$; 3, B. xiamenensis LMG27143 ${ }^{\mathrm{T}}$; 4 B. zhangzhouensis DW5-4 ${ }^{\mathrm{T}} ;$ 5, B. safensis ATCCBAA- $1126^{\mathrm{T}} ;$ 6, B. pumilusNCTC10337 ${ }^{\mathrm{T}} ;$ 7, B. australimaris NH7I_1 ${ }^{\mathrm{T}}$.

\begin{tabular}{ccccccccc}
\hline & $\mathbf{1}$ & $\mathbf{2}$ & $\mathbf{3}$ & $\mathbf{4}$ & $\mathbf{5}$ & $\mathbf{6}$ & $\mathbf{7}$ \\
\hline $\mathbf{1}$ & - & 83.8 & 44 & 39.2 & 36.4 & 36.3 & 35.9 \\
$\mathbf{2}$ & 98.1 & - & 44 & 39.2 & 36.4 & 36.1 & 35.8 \\
$\mathbf{3}$ & 91.3 & 91.3 & - & 42.2 & 37.6 & 36.7 & 37.2 \\
$\mathbf{4}$ & 89.8 & 89.8 & 90.9 & - & 42.3 & 41.7 & 41.6 \\
$\mathbf{5}$ & 88.9 & 88.8 & 89.3 & 90.8 & - & 45.1 & 52 \\
$\mathbf{6}$ & 88.7 & 88.7 & 88.9 & 90.6 & 91.6 & - & 43.5 \\
$\mathbf{7}$ & 88.6 & 88.6 & 89.1 & 90.6 & 93.3 & 91.2 & - \\
\hline
\end{tabular}

\section{Discussion}

We isolated fourteen bacterial strains from pear plant samples showing burn symptoms. Pathogenicity test was performed in greenhouse under natural photoperiod conditions and validated B10 strain as responsible of the symptoms observed in the field.

The Bacillus genus is ubiquitous and can be found in soil (including plant rhizosphere), water, air and food as contaminant $[43,44]$. Decoding pathogen's taxonomy is required to understand its evolution and epidemiology. In this work, the taxonomic identification of B10 isolate was firstly achieved using the 16S RNA gene sequence. This gene has both conserved and variable regions, making it as the most widely used molecular marker for bacterial classification [45]. The sequence analysis indicated that B10 isolate belongs to Bacillus spp., with no evidence regarding the bacterial species (Figure 3). Thus, we performed whole genome sequence (WGS) analysis to acquire insights into the taxonomic affiliation and pathogenicity traits of this isolate. To obtain a finer identification, three genomic makers retrieved from the WGS dataset were used (i.e., $c d a A, g y r A$ and $g y r B$ ). The $c d a A$ gene (previously called $y b b P$ ) was proposed for a more discriminative classification of species within the B. pumilus group [46]. This gene is conserved in almost all Firmicutes (but not all bacteria) and was reported as responsible for the synthesis of cyclic di-AMP, a messenger necessary for cell wall homeostasis [47]. The two other genes, gyr $A$ and $g y r B$, are universally distributed among bacterial species. They encode the A and B subunits of DNA gyrase, respectively, and play an essential role in DNA replication. The phylogenies obtained for these three genes allowed to classify the B10 strain as B. altitudinis. The higher bootstrap values were obtained for the $g y r A$ and $g y r B$ genes compared to 16S rRNA gene, providing a better resolution for taxonomic classification of species from the Bacillus genus. This gene-marker based classification was confirmed using the average nucleotide identity (ANI) and the in silico DNA-DNA hybridization analyzes applied for B10 genome sequence compared to sixty-five species from Bacillus genus (Figure 7 and Table 2).

Some species within the Bacillus genus were reported as phytopathogens such as B. subtilis, the causative agent of the post-harvest soft root [48]. B. pumilus was associated with the bacterial burn on pear in Turkey and with the ginger rhizome rot [14]. In the case of $B$. altitudinis, several reports describe it as a biocontrol agent used against fungal and bacterial pathogens $[49,50]$, or as a plant growth-promoting bacteria (PGPB) able to produce phytohormones or to enhance mineral nutrition [51]. For its pathogenicity effect, the data available are scarce. In a previous study, Elbanna et al., reported B. altitudinis as responsible for the high soft rot on different apple and pear cultivars [8]. Similar results were reported on potatoes [52] and pomegranates [53]. However, so far no study has yet reported virulence factors in $B$. altitudinis and the host range of $B$. altitudinis is not yet determined, which suggests that the application of this bacterium as a biocontrol agent remains hazardous. Thus, we propose that specific genotypes (or pathovars) of 
this bacterial species represent an emerging group of phytopathogens infecting, at least, Rosaceae family.

By comparing the two methods of inoculation, we concluded that the spraying method caused more damages compared to the infiltration method. This indicates that the external contact is sufficient and even more efficient to provoke the disease symptoms. In fact, under the spray inoculation method of B10 isolate, the necrotic lesions on Louise bonne cv. leaves appeared after two weeks, confirming that this bacterial isolate does not need wounds to induce such lesions, suggesting the involvement of hydrolytic enzymes that decompose vegetable cells and tissues. The WGS dataset screening for such enzymes confirmed that B10 genome sequence uncovers, at least, three classes known as plant cell wall degrading enzymes (i.e., carbohydrate esterases, glycoside hydrolases and polysaccharide lyases). Such traits will be investigated within in vitro assays in a future study to evaluate the expression of such enzymes and their potential to degrade plant cell tissues. In addition, a pan-genome analysis will help us to identify the pathovar clade regrouping such pathogenic strains of the B. altitudinis population, with the identification of virulence traits shared at the core and/or accessory genome levels.

\section{Conclusions}

Based on the phylotaxonomic analysis, the pathogenicity tests and the in silico CAZymes screening results, we report here the first genome sequence and characterization of a phytopathogenic B. altitudinis isolate in Morocco. Our study demonstrates that the spraying method remains the best method to test the pathogenicity of $B$. altitudinis on pear plants in planta. In addition, the whole genome sequencing and analysis is more accurate compared to $16 \mathrm{~S}$ rRNA gene sequencing in identifying the tested bacterial isolates. Furthermore, the pathogenicity tests conducted here may be useful in acquiring insights into "pathovars" from this bacterial species. Future work is needed to study the expressed CAZymes and other virulence genes that induce bacterial burn symptoms in pear trees.

Supplementary Materials: The following is available online at https:/ / www.mdpi.com/article/10.3 390/agronomy11071344/s1, Table S1: Full list of carbohydrate active enzymes functionally annotated by HMMER/Hotpep analysis of the Bacillus altitudinis B10 genome.

Author Contributions: N.L. and N.Z. performed field sampling. N.L. and H.J. performed greenhouse pathogenicity experiments. A.M.B. performed whole genome sequencing and bioinformatics/biostatistics analyzes. A.M. performed $16 \mathrm{~S}$ rRNA gene sequencing. N.L. and A.M.B. wrote the manuscript. N.L., K.N., A.M. and A.M.B. reviewed the manuscript. A.D. co-supervised the research work. K.N. supervised the research work. All authors contributed to the article and approved the submitted version. All authors have read and agreed to the published version of the manuscript.

Funding: This work was supported by collaboration with the Laboratory of Microbiology, Signals and Micro-environment (LMSM EA4312), University of Rouen-Normandy, Evreux, France.

Institutional Review Board Statement: Not applicable.

Informed Consent Statement: Not applicable.

Data Availability Statement: The data presented in this study are available on request from the corresponding authors.

Acknowledgments: We acknowledge the contribution of the Normandy Network of Microbial Metagenomics (RNAmb), supported by Région Normandie and European Union (FEDER). We thank Belarbi Lahcen for helping in samples collection in the farms. The authors thank Srinivasan Ramanathan for proofreading the manuscript.

Conflicts of Interest: The authors declare no conflict of interest. 


\section{References}

1. Ikinci, A.; Bolat, I.; Ercisli, S.; Kodad, O. Influence of rootstocks on growth, yield, fruit quality and leaf mineral element contents of pear cv. 'Santa Maria' in semi-arid conditions. Biol. Res. 2014, 16, 47-71. [CrossRef] [PubMed]

2. FAO. Word Pear Production. Food and Agriculture Organisation of the United Nations Crop Statistics, 2013. Available online: http:/ / www.fao.org/faostat/en/\#data (accessed on 24 April 2018).

3. Gonsalves, P.E. As frutas e seus benefícios. In Fructas Que Curam, 2nd ed.; MG: São Paulo, Brazil, 2002; Volume 1, pp. 131-166.

4. FAO. Pear production in Morocco. Food and Agriculture Organisation of the United Nations Crop Statistics, 2016. Available online: http:/ / www.fao.org/faostat/en/\#data (accessed on 30 April 2018).

5. Blancard, D.; Allard, E.; Brest, P. La stemphyliose du poirier ou "macules brunes". Phytoma 1989, 406, 35-37.

6. Vilardell, P. Stemphylium vesicarium en plantaciones de peral. Frutic. Prof. 1988, 18, 51-55.

7. Leu, L.S.; Su, C.C. Isolation, cultivation, and pathogenicity of Xylella fastidiosa, the causal bacterium of pear leaf scorch disease in Taiwan. Plant Dis. 1993, 77, 642-646. [CrossRef]

8. Elbanna, K.; Elnaggar, S.; Bakeer, A. Characterization of Bacillus altitudinis as a New Causative Agent of Bacterial Soft Rot. J. Phytopathol. 2014, 162, 712-722. [CrossRef]

9. Kim, W.G.; Hong, S.K.; Park, Y.S. Occurrence of Anthracnose on Fruits of Asian Pear Tree Caused by Colletotrichum acutatum. Mycobiology 2007, 35, 238-240. [CrossRef]

10. Chatterjee, A. Fire Blight: The Disease and its Causative Agent, Erwinia amylovora. Eur. J. Plant Pathol. 2001, 107, 569. [CrossRef]

11. Momol, M.T.; Aldwinckle, H.S. Genetic diversity and host range of Erwinia amylovora. In The Disease and Its Causative Agent, Erwinia amylovora; Vanneste, J.L., Ed.; CABI: Wallingford, UK, 2000.

12. Ramos, L.S.; Lehman, B.L.; Peter, K.A.; McNellis, T.W. Mutation of the Erwinia amylovora argD Gene Causes Arginine Auxotrophy, Nonpathogenicity in Apples, and Reduced Virulence in Pears. Appl. Environ. Microbiol. 2014, 80, 6739-6749. [CrossRef]

13. Achbani, E.H. Feu bactérien sur Poirier au Maroc. Première apparition de cette brûlure bactérienne sur poirier dans la région de Meknès. Phytoma La Défense Végétaux 2007, 606, 26-28.

14. Kotan, R.; Sahin, F.; Ala, A. Identification and pathogenicity of bacteria isolated from pome fruit trees in the Eastern Anatolia region of Turkey. J. Plant Dis. Prot. 2005, 113, 8-13.

15. Brown, K.L. Control of bacterial spores. Br. Med. Bull. 2000, 56, 158-171. [CrossRef]

16. Turner, J.T.; Backman, P.A. Factors relating to peanut yield increases after seed treatment with Bacillus subtilis. Plant Dis. 1991, 75, 347-353. [CrossRef]

17. Harsh, P.B.; Ray, F.; Jorge, M.V. Biocontrol of Bacillus subtilis against Infection of Arabidopsis Roots by Pseudomonas syringae is facilitated by Biofilm Formation and Surfactin Production. Plant Physiol. 2004, 134, 307-319.

18. Bradbury, F. Guide to Plant Pathogenic Bacteria; CAB International: Wallingford, UK, 1986.

19. Bathily, H.; Babana, A.H.; Samaké, F. Bacillus pumilus a new pathogen on potato tubers in Mali. Afr. J. Microbiol. Res. 2010, 4, 2067-2071.

20. Galal, A.A.; El Bana, A.A.; Janse, J. Bacillus pumilus, a new pathogen on mango plants. Egypt. J. Phytopathol. 2006, 34, 17-29.

21. Saleh, O.I.; Huang, P.I.; Huang, J.S. Bacillus pumilus a cause bacterial Blotch of Immature Balady Peach Egypt. J. Phytopathol. 1997, 145, 447-453. [CrossRef]

22. Li, B.; Qiu, W.; Tan, Q.M.; Su, T.; Fang, Y.; Xie, G.L. Association of a Bacillus species with Leaf and Twig Dieback of Asian pear (Pyrus pyrifolia) in China. J. Plant Pathol. 2009, 91, 705-708.

23. Vaerewijck, M.J.; De Vos, P.; Lebbe, L.; Scheldeman, P.; Hoste, B.; Heyndrickx, M. Occurrence of Bacillus sporothermodurans and other aerobic spore-forming species in feed concentrate for dairy cattle. J. Appl. Microbiol. 2001, 91, 1074-1084. [CrossRef] [PubMed]

24. Adiguzel, A.; Ozkan, H.; Baris, O.; Inan, K.; Gulluce, M.; Sahin, F. Identification and characterization of thermophilic bacteria isolated from hot springs in Turkey. J. Microbiol. Methods 2009, 79, 321-328. [CrossRef]

25. Rintaro, S.; Yousuke, O.; Naoki, K.; Masaru, T. Computer analysis of potential stem structures of rRNA operons in various prokaryote genomes. Gene 2000, 259, 217-222.

26. Peng, Q.; Yuan, Y.; Gao, M. Bacillus pumilus, a Novel Ginger Rhizome Rot Pathogen in China. Plant Dis. 2013, 97, 1308-1315. [CrossRef]

27. Cesbron, S.; Paulin, J.P.; Tharaud, M.; Barny, M.A.; Brisset, M.N. The alternative sigma factor HrpL negatively modulates the flagellar system in the phytopathogenic bacterium Erwinia amylovora under hrp-inducing conditions. FEMS Microbiol. Lett. 2006, 257, 221-227. [CrossRef] [PubMed]

28. Patil, A.G.; Ambadkar, C.V.; Kashid, V.S.; Navgire, K.D. Standardization of methods for pathogenicity of pomegranate bacterial blight caused by Xanthomonas axonopodis pv. Punicae. J. Pharmacogn. Phytochem. 2017, 6, 1763-1765.

29. Nash, A.F.; Gardner, R.G. Tomato early blight resistance in a breeding line derived from Lycopersicon hirsutum PI 126445. Plant Dis. 1988, 72, 206-209. [CrossRef]

30. Schneider, C.A.; Rasband, W.S.; Eliceiri, K.W. NIH Image to ImageJ: 25 years of image analysis. Nat. Methods 2012, 9, 671-675. [CrossRef]

31. R Core Team. R: A Language and Environment for Statistical Computing; R Foundation for Statistical Computing: Vienna, Austria, 2020; Available online: https:/ / www.R-project.org/ (accessed on 10 May 2021). 
32. Andrews, S. FastQC: A Quality Control Tool for High Throughput Sequence Data. 2010. Available online: http://www. bioinformatics.babraham.ac.uk/projects/fastqc/ (accessed on 10 May 2021).

33. Bolger, A.M.; Lohse, M.; Usadel, B. Trimmomatic: A flexible trimmer for Illumina sequence data. Bioinformatics 2014, 30, 2114-2120. [CrossRef]

34. Wick, R.R.; Judd, L.M.; Gorrie, C.L.; Holt, K.E. Unicycler: Resolving bacterial genome assemblies from short and long sequencing reads. PLoS Comput. Biol. 2017, 13, e1005595. [CrossRef]

35. Mikheenko, A.; Prjibelski, A.; Saveliev, V.; Antipov, D.; Gurevich, A. Versatile genome assembly evaluation with QUAST-LG. Bioinformatics 2018, 34, i142-i150. [CrossRef]

36. Bushnell, B. BBMap: A Fast, Accurate, Splice-Aware Aligner; Lawrence Berkeley National Lab. (LBNL): Berkeley, CA, USA, 2014.

37. Tatusova, T.; Dicuccio, M.; Badretdin, A.; Chetvernin, V.; Nawrocki, E.P.; Zaslavsky, L.; Lomsadze, A.; Pruitt, K.D.; Borodovsky, M.; Ostell, J. NCBI prokaryotic genome annotation pipeline. Nucleic Acids Res. 2016, 44, 6614-6624. [CrossRef]

38. Kumar, S.; Stecher, G.; Li, M.; Knyaz, C.; Tamura, K. MEGA X: Molecular evolutionary genetics analysis across computing platforms. Mol. Biol. Evol. 2018, 35, 1547-1549. [CrossRef]

39. Pritchard, L. PYANI: Python Module for Average Nucleotide Identity Analyses. 2017. Available online: https://github.com/ widdowquinn/pyani/releases/tag/v0.2.7 (accessed on 14 December 2020).

40. Meier-Kolthoff, J.P.; Auch, A.F.; Klenk, H.P.; Goker, M. Genome sequence-based species delimitation with confidence intervals and improved distance functions. BMC Bioinform. 2013, 14, 60. [CrossRef]

41. Zhang, H.; Yohe, T.; Huang, L.; Entwistle, S.; Wu, P.; Yang, Z.; Busk, P.K.; Xu, Y.; Yin, Y. dbCAN2: A meta server for automated carbohydrate-active enzyme annotation. Nucleic Acids Res. 2018, 46, W95-W101. [CrossRef]

42. Rawlings, N.D.; Barrett, A.J.; Finn, R. Twenty years of the MEROPS database of proteolytic enzymes, their substrates and inhibitors. Nucleic Acids Res. 2016, 44, D343-D350. [CrossRef]

43. Logan, N.A.; Halket, G. Developments in the taxonomy of aerobic, endospores-forming bacteria. In Endospore-Forming Soil Bacteria; Logan, N., Vos, P., Eds.; Springer: Berlin/Heidelberg, Germany, 2011; Volume 27, pp. 1-29.

44. Collier, F.A.; Elliot, S.L.; Ellis, R.J. Spatial variation in Bacillus thuringiensis/cereus populations within the phyllosphere of broad-leaved dock (Rumex obtusifolius) and surrounding habitats. FEMS Microbiol. Ecol. 2005, 54, 417-425. [CrossRef] [PubMed]

45. Srinivasan, R.; Karaoz, U.; Volegova, M.; MacKichan, J.; Kato-Maeda, M.; Miller, S.; Nadarajan, R.; Brodie, E.L.; Lynch, S.V. Use of 16S rRNA gene for identification of a broad range of clinically relevant bacterial pathogens. PLoS ONE 2015, 10, e0117617. [CrossRef] [PubMed]

46. Espariz, M.; Zuljan, F.A.; Esteban, L.; Magni, C. Taxonomic identity resolution of highly phylogenetically related strains and selection of phylogenetic markers by using genome-scale methods: The Bacillus pumilus group case. PLoS ONE 2016, 11, e0163098. [CrossRef]

47. Gundlach, J.; Mehne, F.M.P.; Herzberg, C.; Kampf, J.; Valerius, O.; Kaever, V.; Stülke, J. An essential poison: Synthesis and degradation of cyclic di-AMP in Bacillus subtilis. J. Bacteriol. 2015, 197, 3265-3274. [CrossRef]

48. Chiu, W.F.; Di, Y.P.; Choue, Y.Y.; Si, F.J. Some bacteria causing dacay of Chinese cabbage in storage. Acta Phytopathologica Sin. 1964, 7, 127-134.

49. Sunar, K.; Dey, P.; Chakraborty, U.; Chakraborty, B. Biocontrol efficacy and plant growth promoting activity of Bacillus altitudinis isolated from Darjeeling hills, India. J. Basic Microbiol. 2015, 55, 91-104. [CrossRef] [PubMed]

50. Lu, X.; Zhou, D.; Chen, X.; Zhang, J.; Huang, H.; Wei, L. Isolation and characterization of Bacillus altitudinis JSCX-1 as a new potential biocontrol agent against Phytophthora sojae in soybean (Glycine max (L.) Merr). Plant Soil 2017, 416, 53-66. [CrossRef]

51. Kumaravel, S.; Thankappan, S.; Raghupathi, S.; Uthandi, S. Draft genome sequence of plant growth-promoting and droughttolerant Bacillus altitudinis FD48, isolated from rice phylloplane. Genome Announc. 2018, 6, e00019-18. [CrossRef] [PubMed]

52. Kumvinit, A.; Akarapisan, A. Characterization of blackleg and soft rot from potato in northern Thailand. J. Phytopathol. 2019, 167, 655-666. [CrossRef]

53. Liu, Q.; Li, D.; Hu, H.; Hu, H.; Huang, Q.; Zhang, Y.; Zhou, F.; Song, P.; Guan, Y.; Bu, R.; et al. First report of Bacillus altitudinis causing seed rot of pomegranate in China. Australas. Plant Pathol. 2021, 50, 427-429. [CrossRef] 